\title{
The Long-Term Effects of Adolescent Social Defeat Stress on Oligodendrocyte Lineage Cells and Neuroinflammatory Mediators in Mice
}

This article was published in the following Dove Press journal:

Neuropsychiatric Disease and Treatment

\author{
Yingjuan $\mathrm{Xu}{ }^{\prime}$ \\ Zeman Fang' \\ Cairu $\mathrm{Wu}^{\prime}$ \\ Haiyun $\mathrm{Xu}^{1,2}$ \\ Jiming Kong $\mathbb{B D}^{3}$ \\ Qingjun Huang' \\ Handi Zhang (D)
}

'Shantou University Mental Health Center, Shantou, Guangdong, People's Republic of China; ${ }^{2}$ Affiliated Kangning Hospital, School of Psychiatry, Wenzhou Medical University, Wenzhou, Zhejiang, People's Republic of China; ${ }^{3}$ Department of Human Anatomy and Cell Science, University of Manitoba, Winnipeg, MB, Canada
Correspondence: Handi Zhang Shantou University Mental Health Center, Shantou, Guangdong 515065, People's Republic of China

Tel +86-754-829020I4

Fax +86-754-825I0525

Email zhanghandi78@I63.com
Objective: Adverse childhood and adolescent experiences are associated with the emergences of psychopathology later in life and have negative consequences on white matter integrity. However, this adversity-induced white matter impairment remains not fully investigated.

Methods: Adolescent Balb/c mice were subjected to intermittent social defeat stress once a day during postnatal days 25 to 40 . Then, the subjects were allowed to recover for three weeks before sacrifice. At the end, oligodendrocyte (OL) lineage cells, cell proliferation, and microglia activation, as well as myelin basic protein (MBP) levels in frontal cortex and hippocampus were evaluated. The levels of interleukin (IL)-1 $\beta$ and IL- 6 in the brain regions were assessed.

Results: MBP protein level in frontal cortex, but not in the hippocampus of defeated mice, decreased significantly compared to controls. The numeral densities of mature OLs, oligodendrocyte progenitor cells, and proliferating cells in medial prefrontal cortex were comparable between the defeated mice and controls. The defeated mice, however, showed significantly higher IL-1 $\beta$ level, although IL-6 level and numeral density of microglia in frontal cortex did not change relative to controls.

Conclusion: These results indicate that effects of intermittent social defeat stress on the white matter integrity and OL lineage cells in mouse brain are region- and developmental stage-specific. Upregulated IL-1 $\beta$ may contribute to this negative consequence though the underlying mechanism remains to be investigated.

Keywords: social defeat stress, adolescence, myelin, oligodendrocyte lineage cells, interleukin-1 $\beta$

\section{Introduction}

Childhood and adolescent adversities in humans are believed to increase the risk of psychopathology developed in adulthood, including impaired social behavior and cognitive functions, major depressive disorder and anxiety disorders, as well as suicide attempts. ${ }^{1-6}$ On the other hand, there is increasing studies reporting impaired white matter integrity in some patients with psychiatric disorders, suggesting a presumable role of the white matter pathology in the pathogenesis of psychiatric disorders. ${ }^{7-9}$ In addition, childhood and adolescent adversities have been associated with chronic inflammation and brain morphological changes including alterations in white matter structural integrity. ${ }^{10-13}$

Social defeat stress is considered as an ethologically relevant stressor and a good model of physical abuse during childhood and adolescence. It is mimicked in animal 
studies by adopting the paradigm of repeated social defeats on consecutive days. ${ }^{14-17}$ Some of previous animal studies reported that early-life social defeat stress results in social and mood-related behavior abnormalities in adulthood; ${ }^{18-20}$ while the others showed oligodendrocyte (OL)/myelin abnormalities resulted from social defeat stress paradigms in adult animals. ${ }^{21-25}$ In contrast, few studies looked at possible effects of social defeat stress on white matter integrity in juvenile or adolescent animals, although bullying events often happen in school students and adolescents in societies, which is alike to an intermittent social defeat paradigm in animals. $^{26}$ In a recent study, we adapted the repeated social defeat paradigm into an intermittent social defeat stress procedure in adolescent Balb/c mice. We found intermittent social defeat paradigm impaired the sociability of mice, resulted in neurochemical changes, and diminished protein levels of myelin basic protein (MBP), a myelin structure protein, in mouse brain at adulthood. ${ }^{27}$ Pertinently, socially isolated adolescent mice exhibited deficits in OL/myelin development as evidenced by simplified OL morphology and decreased expression of OL markers. ${ }^{28,29}$ Nevertheless, the long-term effects of social stress during childhood and adolescence on OL/myelin development and the underlying molecular and cellular mechanisms remain to be elucidated.

Central nervous system (CNS) myelin is produced by mature OLs, which develop from oligodendrocyte progenitor cells (OPCs), also known as NG2 cells. OPCs present in both adolescence and adult brain and are able to proliferate in response to various stimulations. ${ }^{30}$ Evidence has shown that the proliferation of OPCs and differentiation of them in the brain can be affected by a variety of environmental factors including early life adverse events/experience which is regarded as an important aspect of neural plasticity. ${ }^{29-31}$ Of the brain regions showing alterations in OL development and myelination in response to stressful experiences, medial prefrontal cortex (mPFC), hippocampus, nucleus accumbens and amygdala are more extensively investigated..$^{21-25,29,32,33}$ The present study focused the observation on mPFC and hippocampus as they are known to be particularly vulnerable to stressful conditions. ${ }^{34}$ Microglia are the primary CNS resident macrophages and constantly surveil their microenvironment in the brain. ${ }^{35}$ Recent studies suggest that microglia and related cytokines, including interleukin (IL)-1 $\beta$ and IL-6, play essential roles in OPCs maintenance and maturation, myelinogenesis and remyelination processes. ${ }^{36,37}$ Here we examined effects of intermittent social defeat stress during the early adolescent stage on the cytokines IL- $1 \beta$ and IL-6, in addition to the observation on OL lineage cells, cell proliferation and microglia.

\section{Materials and Methods Animals and Drug Treatments}

Male, postnatal day (PD) 25, Balb/c mice and adult retired male CD1 breeders were used in this study. They were purchased from the Vital River Laboratories (Beijing, China). $\mathrm{Balb} / \mathrm{c}$ mice were housed in groups of 3-4 in standard polypropylene cages on a 12-h light/dark cycle (lights on at 08:00) with food and water available ad libitum. Experiments were conducted in compliance with the guideline set up and approved by the Animal Care and Use Committee of Shantou University Medical College. Bromodeoxyuridine (BrdU; Sigma-Aldrich, St. Louis, MO, USA), a thymidine analog that labels dividing cells in the S-phase of the cell cycle, was dissolved in phosphate-buffered saline (PBS; $\mathrm{pH}$ 7.4) and administrated (100 mg/kg, i.p.) 4 times at $24-\mathrm{h}$ intervals, 17 days after the last defeat episode. The mice were sacrificed for immunohistochemical staining $24 \mathrm{~h}$ after the last BrdU injection.

\section{Social Defeat Stress and Experimental Design}

Adolescent Balb/c mice were randomly assigned to either a control or stress group. The social defeat stress paradigm was performed as previously described. ${ }^{27}$ Prior to social defeat stress, CD1 mice were screened for their levels of aggression and those who attacked Balb/c mice within 30 seconds in two screening tests were chosen for the intruder-resident social defeat paradigm. For each stress session, adolescent Balb/c mice (at PD 25) were placed into the same compartment as the CD1 aggressor for $1 \mathrm{~min}$, and then housed for another 30 min in the compartment adjacent to their respective CD1 aggressor. After each stress episode, Balb/c intruders were returned to their home cage. This procedure was repeated for three consecutive days followed by a day off. Over a course of 15 days, the mice in the stress group experienced 12 social defeat stress sessions with different CD1 aggressors each session. The mice in the control group were handled at the same time without exposure to a resident aggressor. Immediately after the last defeat episode (PD 40), both stressed and nonstressed mice were reared in their home cages under the same conditions. Three weeks later they were sacrificed under deep anaesthesia and their brains were processed for immunohistochemical staining, Western blot analysis and enzyme-linked immunosorbent assay (ELISA). 


\section{Immunohistochemical Staining}

The Balb/c mice were anaesthetized with isoflurane and transcardially perfused with PBS, followed by $4 \%$ paraformaldehyde in PBS. The brains were post-fixed in the same fixative overnight at $4^{\circ} \mathrm{C}$, and then soaked in $30 \%$ (w/v) sucrose in PBS for $24-48 \mathrm{~h}$ at $4^{\circ} \mathrm{C}$. Serial coronal sections $(30 \mu \mathrm{m})$ were cut on a cryostat (Leica, Wetzler, Germany). Sections of the frontal cortex between bregma $+1.54 \mathrm{~mm}$ and $+1.98 \mathrm{~mm}$ were collected for immunohistochemical staining. For immunostaining of adenomatous polyposis coli (APC), NG2 chondroitin sulfate proteoglycan (NG2) and ionized calcium binding adapter molecule 1 (Iba-1), free-floating sections were pre-treated with $3 \%$ hydrogen peroxide in PBS for $20 \mathrm{~min}$ at $22^{\circ} \mathrm{C}$, washed in PBS, and incubated in a blocking solution composed of $0.3 \%$ Triton $\mathrm{X}-100$ and $5 \%$ normal rabbit or goat serum for $30 \mathrm{~min}$ at $22^{\circ} \mathrm{C}$. The sections were subsequently incubated with the primary antibody against APC (clone CC-1, 1:200; EMD Millipore, Burlington, MA, USA), NG2 (1:200; Chemicon, CA, USA) or Iba-1 (1:1000, Wako, Japan), in the blocking solution overnight at $4^{\circ} \mathrm{C}$. The above antibodies were used to examine the mature OLs (anti-APC), OPCs (anti-NG2) and microglia (anti-Iba-1), respectively. For BrdU immunostaining, free-floating sections were incubated in $1 \mathrm{~N} \mathrm{HCL}$ for 50 min at $40^{\circ} \mathrm{C}$, washed in PBS, and treated with $0.01 \%$ trypsin solution $\left(\mathrm{w} / \mathrm{v}\right.$, prewarmed to $40^{\circ} \mathrm{C}$ ) for $10 \mathrm{~min}$ at $22^{\circ} \mathrm{C}$. Sections were then rinsed in PBS and incubated in $1 \%$ hydrogen peroxide in methanol for $20 \mathrm{~min}$ at $22^{\circ} \mathrm{C}$. The sections were subsequently washed with PBS, incubated in 5\% bovine serum albumin (BSA) blocking solution ( $\mathrm{w} / \mathrm{v}, \mathrm{BSA}+0.5 \%$ Tween 20 in PBS) for 20 min at $22^{\circ} \mathrm{C}$, and treated with the primary antibody against BrdU (1:200, Sigma-Aldrich, St. Louis, MO, USA) overnight at $4^{\circ} \mathrm{C}$. For both BrdU and other immunostaining, sections were then rinsed in PBS and incubated in biotinylated secondary antibodies (1:1000; VectorLabs, Burlingame, CA, USA) for $2 \mathrm{~h}$ at $22^{\circ} \mathrm{C}$. Following rinses in PBS, sections were incubated in avidinbiotin-horseradish peroxidase solution from the Vectastain (Elite) ABC kits (VectorLabs, Burlingame, CA, USA) for 30 $\min$ at $22^{\circ} \mathrm{C}$. Finally, sections were developed with DAB kit (VectorLabs, Burlingame, CA, USA) following the manufacturer's instructions.

\section{Western Blot}

Prefrontal cortex and hippocampal samples were homogenized in RIPA lyses buffer (50 mM Tris, $150 \mathrm{mM} \mathrm{NaCl}$, $1 \%$ NP40, $0.5 \%$ sodium deoxycholate, and $0.1 \%$ SDS) with freshly added protease inhibitor cocktail (Sigma-
Aldrich, St. Louis, MO, USA). The suspension was collected after centrifugation at $12,000 \mathrm{rpm}$ for $10 \mathrm{~min}$ at $4^{\circ} \mathrm{C}$. Total protein concentration was quantified using a BCA kit (Beyotime Biotechnology, Shanghai, China), and protein samples were loaded onto $12 \%$ mini precast Tris-glycine gel subjected to electrophoresis at $70 \mathrm{~V}$ and $110 \mathrm{~V}$ until the bromophenol blue reached the bottom of the gel. The proteins were then transferred to PVDF membranes. Membranes were incubated in a blocking solution of $5 \%$ non-fat milk in PBS for $1 \mathrm{~h}$ at $22^{\circ} \mathrm{C}$, followed by incubation in a blocking solution containing the primary antibody to MBP (1:1000; Santa Cruz Biotechnology, Dallas, TX, USA) overnight at $4{ }^{\circ} \mathrm{C}$. The membranes were then washed with PBS, followed by incubation in the blocking solution containing the rabbit anti-goat secondary antibodies (1:10,000; VectorLabs, Burlingame, CA, USA). After three rinses in PBS, immunoreactive bands were developed using an ECL detection kit (Thermo Fisher Scientific, Waltham, MA, USA). Positive signals were visualized and quantified using a ChemiDox XRS+ imaging system (Bio-rad, Hercules, CA, USA). To confirm equal amounts of loading samples, $\beta$-actin was also labeled (1:5000; Sigma, St. Louis, MO, USA) through the same procedures as described above.

\section{Image Analysis}

Images containing the $\mathrm{mPFC}$ region (from bregma $+1.54 \mathrm{~mm}$ to $+1.98 \mathrm{~mm}$ ) were captured under a Nikon microscope (Nikon Instruments Inc, NY, USA). Three brain sections per animal with an interval of $150 \mu \mathrm{m}$ were selected for quantitative analysis. APC, NG2, Iba-1 and BrdU positive cells were counted and the results were expressed as the number of positive cells per $\mathrm{mm}^{2}$.

\section{Elisa}

The extraction and quantification of total protein in frontal cortex region were performed as described in Western blot section. IL-1 $\beta$ and IL-6 levels were determined using an ELISA kit (R\&D System, Inc., Minneapolis, MN, USA), according to the manufacturer's protocol. The levels of cytokine were presented as standardized concentrations (pg cytokine/mg protein).

\section{Statistical Analysis}

All data were expressed as mean \pm SEM. Independent samples $t$ test was performed to determine the differences between the control and stress group. When a $\mathrm{P}$ value was $<0.05$, the difference was considered statistically significant. 


\section{Result}

\section{Intermittent Social Defeat Stress}

\section{Decreased MBP Levels in Frontal Cortex} of Mice

MBP, a structural protein specifically expressed in the myelin sheath, was assessed. As shown in Figure 1A, intermittent social defeat stress exposure during early adolescence resulted in a significant decrease in MBP protein level in frontal cortex. Statistical analysis showed a significant difference in MBP protein level between the normal control group and the stress group (Figure 1B). However, the expression of MBP protein was not altered in hippocampus of mice exposed to intermittent social defeat stress during early adolescence compared to normal control mice when evaluated 3 weeks after the last stress exposure as shown in Figure 1C and D.

\section{Intermittent Social Defeat Stress Showed No Effect on Mature OL and OPC Numbers in mPFC of Mice}

The protein APC is an established marker of mature OLs in CNS. NG2 is specially expressed by OPCs in CNS.
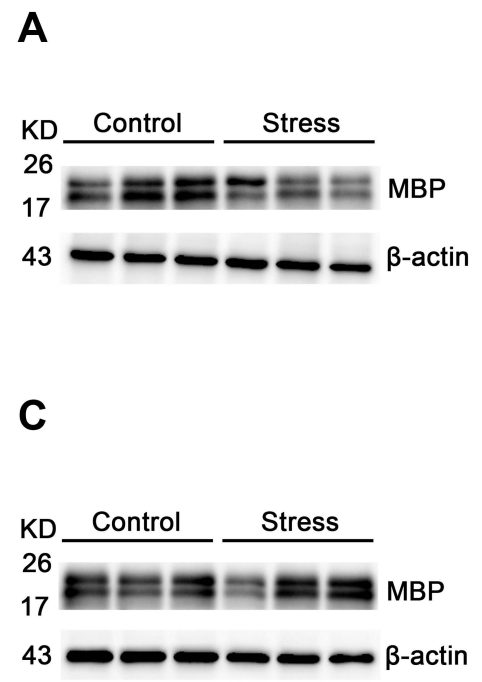

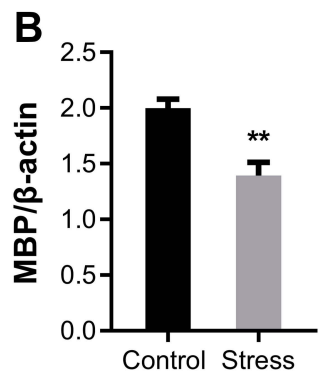

D

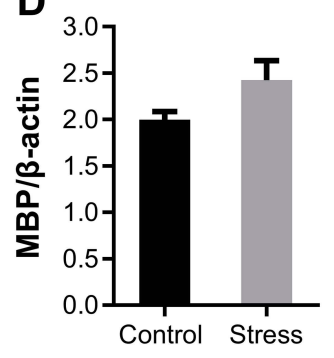

Figure I Effects of intermittent social defeat stress on myelin basic protein (MBP) protein level in frontal cortex and hippocampus.

Notes: MBP protein levels were evaluated 3 weeks after the last stress exposure. (A) A representative western-blot image of MBP immunoreactive bands from frontal cortex was shown. (B) The bar graph showed the quantitative data of the relative amount of MBP in frontal cortex. (C) A representative western-blot image of MBP immunoreactive bands from hippocampus was shown. (D) The bar graph showed the quantitative data of the relative amount of MBP in hippocampus. Data are expressed as mean \pm SEM ( $n=6 /$ group), ${ }^{* *} p<0.01$, compared to control group. Abbreviation: KD, kilodalton.
Intermittent social defeat stress during early adolescence did not induce evident loss of APC positive OLs (Figure $2 \mathrm{~A}$ ) and NG2 positive OPCs (Figure 2C) in $\mathrm{mPFC}$ when evaluated 3 weeks after the last stress exposure. There was no statistically significant difference in the number of APC positive cells (Figure 2B) or NG2 positive cells (Figure 2D) between the stress and the control group.

\section{Intermittent Social Defeat Stress Had No Effect on Cell Proliferation in mPFC of Mice}

BrdU has been used as a principal marker for labeling proliferating cells. The number of BrdU positive cells was not changed in $\mathrm{MPFC}$ of mice exposed to intermittent social defeat stress during early adolescence when evaluated 3 weeks after the last stress exposure (Figure 3A). There was no statistically significant difference between the stress and the control group (Figure 3B).

\section{Intermittent Social Defeat Stress Did Not Change Microglia Number, but Increased IL-I $\beta$ Levels in mPFC of Mice}

Immunohistochemical staining was performed using the antibody to Iba-1, a marker for microglia. Iba-1 positive cells in both control and stress group showed similar ramified morphology with densely staining cell bodies and several highly branched processes (Figure 4A). The number of Iba-1 positive microglia was also comparable between the control and stress group as shown in Figure 4A. There was no statistically significant difference on the Iba-1 positive cell number between the two groups (Figure 4B). The levels of proinflammation cytokine IL-6 and IL-1 $\beta$ in frontal cortex were evaluated by ELISA. As shown in Figure 5A, intermittent social defeat stress exposure during early adolescence induced a significant increase of IL- $1 \beta$ protein level in frontal cortex when evaluated 3 weeks after the last stress exposure. However, the level of IL-6 protein was not altered in $\mathrm{mPFC}$ of mice exposed to intermittent social defeat stress during early adolescence compared to normal control mice as shown in Figure 5B.

\section{Discussion}

Our data show that social defeat stress decreased the levels of MBP in the $\mathrm{mPFC}$, but not in the hippocampus of adolescent male Balb/c mice, 3 weeks post last defeat. This result indicates that myelin in the $\mathrm{mPFC}$ is more susceptible to stress than that in the hippocampus in 
A
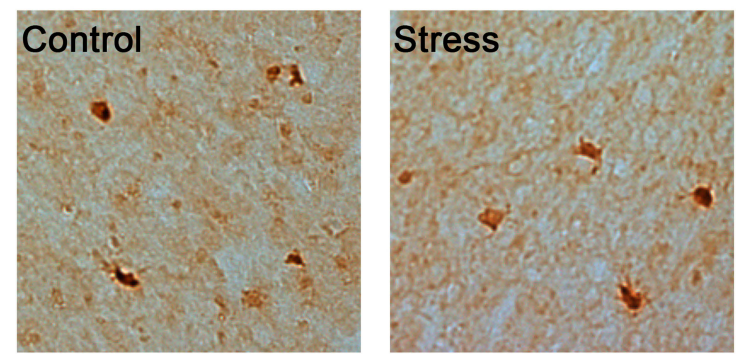

C

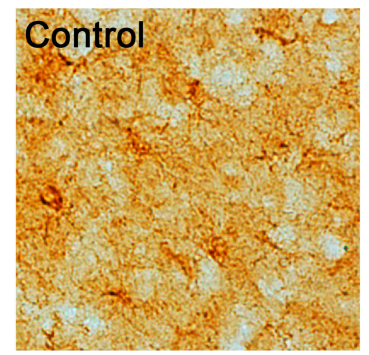

B

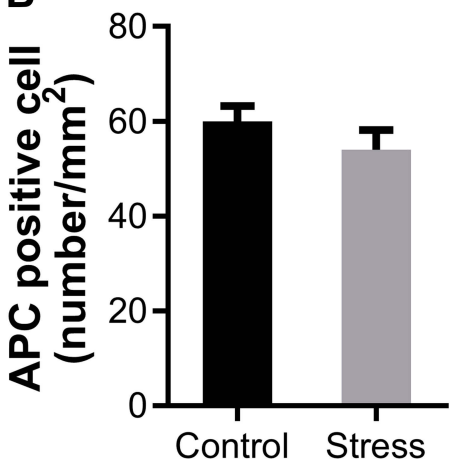

D

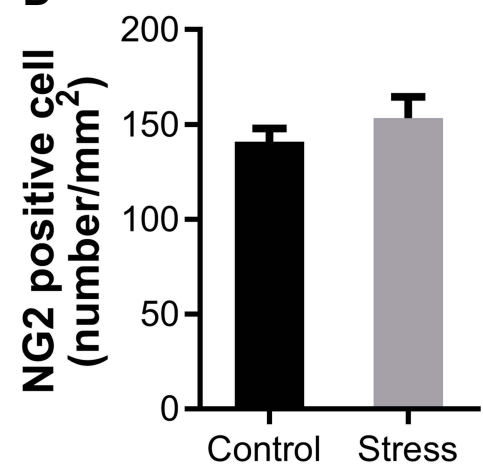

Figure 2 Effects of intermittent social defeat stress on the numbers of mature oligodendrocytes (OLs) and oligodendrocyte progenitor cells (OPCs) in medial prefrontal cortex (mPFC).

Notes: The numbers of adenomatous polyposis coli (APC) positive OLs and NG2 chondroitin sulfate proteoglycan (NG2) positive OPCs were evaluated 3 weeks after the last stress exposure. (A) Representative images of APC-immunostaining in the mPFC were shown. (B) The bar graph exhibited the quantitative data of APC positive OL number. (C) Representative images of NG2-immunostaining in the mPFC were shown. (D) The bar graph exhibited the quantitative data of NG2 positive OPC number. Data are expressed as mean \pm SEM ( $n=3-4$ /group). The scale bar represents $25 \mu \mathrm{m}$.

adolescent mice. The mPFC is a key structure regulating cognition and emotion and its maturation continues from adolescence into early adulthood. Compromised myelin in the mPFC may underlie the long-term emotion-related behavioral changes induced by social defeat stress in adolescent animals as reported in previous studies. ${ }^{19,27}$ The hippocampus plays a critical role in episodic memory formation and emotion-related behavior, and undergoes volumetric changes during adolescence. ${ }^{38-40}$ Although neurogenesis in the hippocampus has been frequently
A
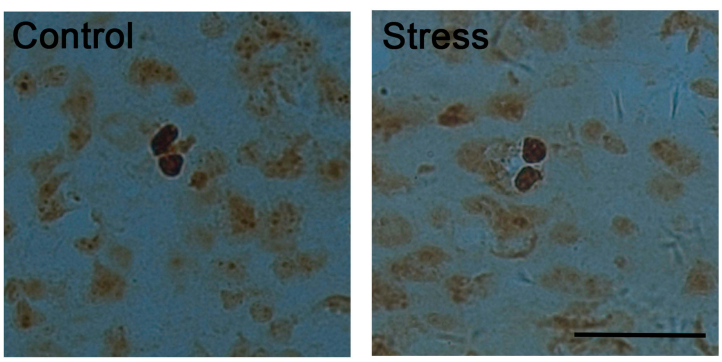

B

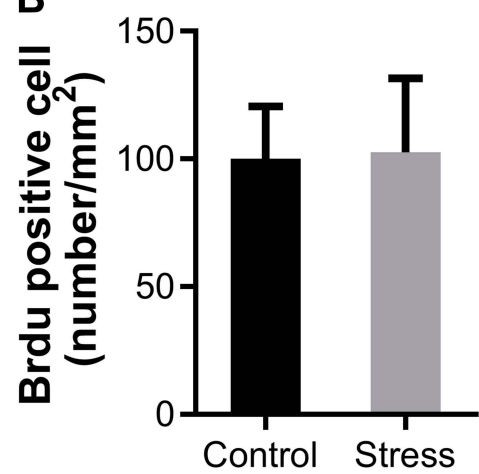

Figure 3 Effects of intermittent social defeat stress on the number of bromodeoxyuridine (BrdU) positive cells.

Notes: BrdU was administrated during the last four days of social defeat stress and the number of BrdU positive cells was evaluated 3 weeks after the last stress exposure. (A) Representative images of BrdU-immunostaining in the medial prefrontal cortex (mPFC) were shown. (B) The bar graph exhibited the quantitative data of BrdU positive cell number. Data are expressed as mean \pm SEM $(n=3$ /group). The scale bar represents $25 \mu \mathrm{m}$. 
A

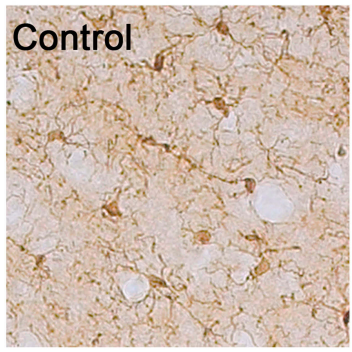

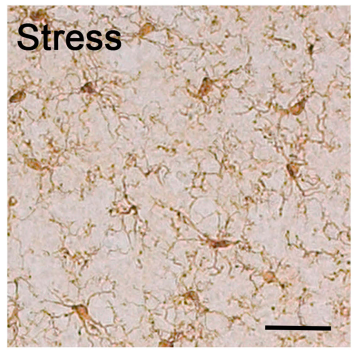

B

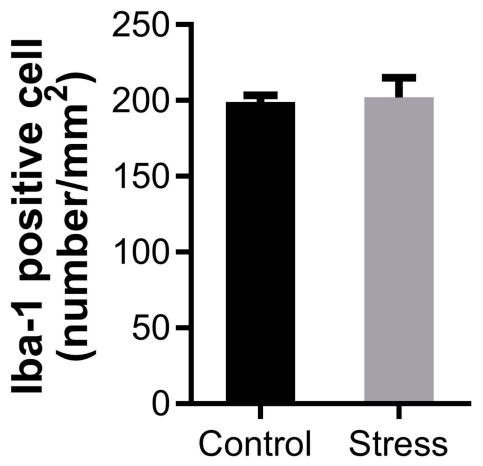

Figure 4 Effects of intermittent social defeat stress on the morphology and number of ionized calcium binding adapter molecule I (lba-I) positive microglia. Notes: The changes of the morphology and number of Iba-I positive microglia were evaluated 3 weeks after the last stress exposure. (A) Representative images of lbalimmunostaining in the medial prefrontal cortex (mPFC) were shown. (B) The bar graph exhibited the quantitative data of lba-I positive cell number. Data are expressed as mean \pm SEM $(n=4 /$ group $)$. The scale bar represents $25 \mu \mathrm{m}$.

demonstrated susceptible to stress exposure, ${ }^{41}$ our results indicate this damaging effect of stress may not extend to oligodendrogenesis/myelination in adolescent mice as inferred from the unaltered MBP level in this brain region. This is distinct from the other study showing increases in oligodendrogenesis and MBP expression within the hippocampus of adult rodents exposed to 7-day restrain stress. ${ }^{32}$ This inconsistency may be related to different stress paradigm, age of animals, and subregions of hippocampus examined in the studies. In other words, these results suggest that the effect of stress on MBP level is related to age, stress paradigm and/or region of interest.

Our results demonstrate that the numbers of mature OLs, OPCs and proliferating cells in the mPFC were not
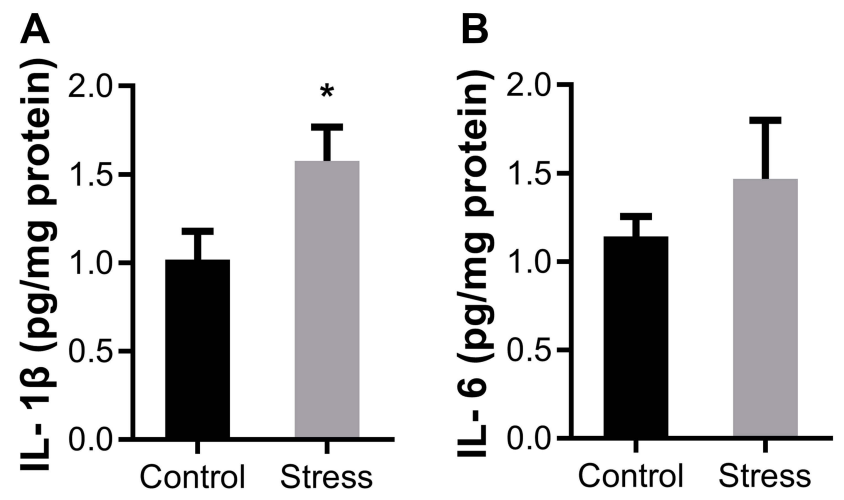

Figure 5 Effects of intermittent social defeat stress on the levels of cytokines interleukin (IL) $-I \beta$ and IL-6.

Notes: The levels of IL-I $\beta$ and IL- 6 in prefrontal cortex (PFC) were evaluated by ELISA 3 weeks after the last stress exposure. (A) The bar graph showed the quantitative data of IL-I $\beta$ protein level (B) The bar graph showed the quantitative data of IL-6 protein level. Data are expressed as mean \pm SEM ( $n=6-8$ /group), ${ }^{*} p<$ 0.05 , compared to control group. altered when examined 3 weeks after social defeat stress, indicating that the developmental process of $\mathrm{OL}$ lineage cells, including the proliferation and differentiation of OPCs, are not affected by social defeat stress and may not contribute to the altered levels of MBP in the mPFC. The effect of social defeat stress on the number of mature OLs in the mPFC is mixed. Previous studies have shown no changes in mature OL number in mPFC of mice exposed to chronic social defeat stress in adulthood ${ }^{25}$ and adolescence, ${ }^{27}$ whereas other studies have reported reduced numbers of mature OLs in adult mice susceptible to social defeat stress. ${ }^{24}$ Also, effects of chronic social defeat stress on NG2 positive cells are inconsistent. ${ }^{22,24}$ Adult animals exposed to 10-day social defeat stress showed many more NG2 positive cells in the mPFC of susceptible mice $24 \mathrm{~h}$ post the last episode of stress. ${ }^{24}$ In contrast, 8-day social defeat stress decreased NG2 glial proliferation and cell number in stress-susceptible mice immediately or 10 days after the last defeat exposure. ${ }^{22}$ The discrepancy on the OL lineage cells among these studies may relate to the differences in stress timing, paradigm and the period between the end of stress and the sample collection.

Microglia are resident immune cells in CNS. They quickly become activated upon encountering signs indicating injury or infection in the brain and serve as powerful source of cytokines which are cytotoxic or protective to other cells of CNS, such as neurons and OLs. ${ }^{42}$ IL-1 $\beta$ and IL-6 are two major proinflammation cytokines produced by microglia and participate in the regulation of OL development, myelination and remyelination. ${ }^{37}$ 
Our data demonstrate that the elevation of IL- $1 \beta$ levels coexisted with myelin impairment in the $\mathrm{mPFC}$ of mice exposed to social defeat stress in adolescence, whereas the levels of IL-6 and the number of microglia were not altered, suggesting that social defeat stress might cause myelin impairment by up-regulation of IL- $1 \beta$ protein. In line with our reports, previous studies have shown that the induction of mRNA levels of IL-1 $\beta$ exist concurrently with the decrease of myelin protein expression in cuprizoneinduced demyelinating mice ${ }^{43}$ and high-dose alcohol exposed rats. ${ }^{44}$ In vitro and in vivo studies have found IL-1 $\beta$ exerted toxic effect on OL development and maturation. ${ }^{45-48}$ However, the different effects of IL- $1 \beta$ on $\mathrm{OL} /$ myelin were also reported, exemplified by the studies showing that IL- $1 \beta$ promotes maturation and survival of OLs in vitro ${ }^{49}$ and facilitates remyelination in cuprizone-induced demyelinating mice. ${ }^{43}$ Therefore, an alternative possibility is that IL- $1 \beta$ might promote myelin repairment in mice exposed to social defeat stress. The elevation of IL-1 $\beta$ may be a compensatory action to social defeat stress-induced myelin impairment. In the current study, we were not able to discern if one of the two mechanisms was the primary or if they both have a role mediating the effect of social defeat stress on myelin. Future studies are needed to clarify the role of IL- $1 \beta$ on myelin impairment in adolescent mice exposed to social defeat stress.

Broad spectrum effects of social defeat stress on microglial activation have been observed, such as increased or reduced cell number, enlarged or decreased cell size and altered ramify state. ${ }^{50-52}$ Our data show that the number of Iba-1 positive microglia in the mPFC is not changed in stressed mice when examined 3 weeks after the last stress episode. Previous studies have shown dynamic changes in microglial activation in stressed mice, and the initial activation is required for later behavioral and neuropathological alterations induced by stress exposure. ${ }^{53,54}$ We offer an alternative explanation that the intermittent social defeatinduced changes in microglia had recovered to normal condition during the 3-week recovery period after the last stress exposure. This explanation is not conflict with the observed microglia activation identified in brains of adult mice exposed to stress. Further experiments are needed to track the dynamic changes of microglial during and after social defeat stress in adolescent animals.

IL-6 has been demonstrated to be involved in OL differentiation, survival and remyelination. ${ }^{37,55} \mathrm{~A}$ recent study shows that social isolation alters remyelination via modulation of IL-6 expression in cuprizone-induced adult demyelinating mice. ${ }^{56}$ Different from this report, the present study indicates that IL-6 protein level in the mPFC is not altered in mice exposed to social defeat stress during early adolescence, suggesting that IL-6 might not play a major role in social defeat-induced myelin impairment in this experimental condition. In agreement with this study, a previous study found no change in IL-6 level in the prefrontal cortex of hamsters exposed to intermittent social defeat stress during the entire juvenile period. ${ }^{57}$ The discrepancy in these studies may be related to the differences in the age of animals when experiencing stress and the stress paradigms employed. ${ }^{58,59}$

Recently, the underlying biological and neurobiological mechanisms mediating the effect of childhood and adolescent adversities on psychopathology vulnerability have been scrutinized. Some of the persistent biological alterations were associated with childhood and adolescent adversities, such as changes in neuroendocrine, neurotransmitter systems and immune system. These individual changes may interact with each other and contribute to specific alterations in brain structures and functions involved in cognitive and emotional regulation. ${ }^{60,61}$ Microglia express diverse receptors, which permit them to integrate and response to stress-induced hormones, neural and immune products including glucocorticoids, corticotropin-releasing factor and cytokines. ${ }^{62,63}$ The evidence also exists showing that OL development and myelination are influenced by stress hormones. ${ }^{32,64}$ While the present study focused on the role of microglia and cytokines in the myelin pathology, future research should address the interactions between neuroendocrine and immune system under the myelin pathology condition induced by the early life stress.

Relevant to this study, a large body of clinical studies has reported that the changed levels of cytokines and microglia activation are important pathophysiological changes in mood disorders. ${ }^{65}$ Increasing evidence supports that anti-inflammatory therapeutic adjunct can effectively alleviate depressive symptoms in patients suffering from mood disorders. ${ }^{66}$ Collectively, these studies suggest that neuroinflammation may contribute to pathogenesis of stress-related disorders and may serve as a promising therapeutic target for the treatment-resistant mood disorders.

Some limitations of the present study should not be ignored. First, significant or complete recovery from the social defeat stress-induced changes might happen during the three weeks recovery period after the last social defeat 
stress episode. As such, it is hard to know if changes already recovered or they really did not happen in the defeated mice. Second, female subjects were not included in this study. Therefore, the conclusion and interpretations cannot be generalized to human bullying in which girls are also victims. ${ }^{26}$ Third, only mPFC and hippocampus were examined. Other brain structures implicated in the regulation of stress and emotion, such as amygdala and nucleus accumbens, should be investigated too.

\section{Conclusion}

With the intermittent social defeat stress paradigm administered to adolescent mice, this study provided relatively long-term results of the paradigm on the white matter integrity, OLs, and microglia in victims, which complement the extant data resulted from repeated social defeat stress on consecutively days administered at adulthood. The persistent decrease in MBP protein level in PFC of defeated mice indicates this brain region is relatively high susceptible to this paradigm and less resilient in terms of myelin sheath integrity. The co-existing elevated levels of IL-1 $\beta$ in the same brain region of defeated mice suggest a possible role of this proinflammatory cytokine in maintaining myelin sheath at normal condition or in facilitating the recovery process of deficit myelin sheath. In conclusion, PFC and MBP may be regarded as potential therapeutic targets in patients with mental disorders relevant to early life adversities.

\section{Abbreviations}

OL, oligodendrocyte; MBP, myelin basic protein; IL, interleukin; CNS, central nervous system; OPCs, oligodendrocyte progenitor cells; mPFC, medial prefrontal cortex; PD, postnatal day; BrdU, bromodeoxyuridine; PBS, phosphatebuffered saline; ELISA, enzyme-linked immunosorbent assay; APC, adenomatous polyposis coli; NG2, NG2 chondroitin sulfate proteoglycan; Iba-1, ionized calcium binding adapter molecule 1; BSA, bovine serum albumin.

\section{Ethics Approval}

Experiments in this work were conducted in compliance with the guideline set up and approved by the Animal Care and Use Committee of Shantou University Medical College (Reference No. SUMC2016-117).

\section{Data Sharing Statement}

We have made our data publicly available through the Open Science Framework (link: https://osf.io/w8rnt/).

\section{Author Contributions}

All authors made substantial contributions to conception and design, acquisition of data, or analysis and interpretation of data; took part in drafting the article or revising it critically for important intellectual content; gave final approval of the version to be published; and agree to be accountable for all aspects of the work.

\section{Funding}

This work was supported by the Grants from the Natural Science Foundation of Guangdong Province (grant number 2017A030313824) and Key Disciplinary Project of Clinical Medicine under the Guangdong High-level University Development Program (grant number 00218119101). The sponsors had no involvement in any of the stages from study design to submission of the paper for publication.

\section{Disclosure}

The authors report no conflicts of interest in this work.

\section{References}

1. Green JG, McLaughlin KA, Berglund PA, et al. Childhood adversities and adult psychiatric disorders in the national comorbidity survey replication I: associations with first onset of DSM-IV disorders. Arch Gen Psychiatry. 2010;67(2):113-123. doi:10.1001/archgenpsychiat ry.2009.186

2. Gilbert R, Widom CS, Browne K, Fergusson D, Webb E, Janson S. Burden and consequences of child maltreatment in high-income countries. Lancet. 2009;373(9657):68-81. doi:10.1016/S01406736(08)61706-7

3. Infurna MR, Reichl C, Parzer P, Schimmenti A, Bifulco A, Kaess M. Associations between depression and specific childhood experiences of abuse and neglect: a meta-analysis. $J$ Affect Disord. 2016;190:47-55. doi:10.1016/j.jad.2015.09.006

4. Teicher MH, Samson JA, Anderson CM, Ohashi K. The effects of childhood maltreatment on brain structure, function and connectivity. Nat Rev Neurosci. 2016;17(10):652-666. doi:10.1038/nrn.2016.111

5. Ford E, Clark C, Stansfeld SA. The influence of childhood adversity on social relations and mental health at mid-life. J Affect Disord. 2011;133(1):320-327. doi:10.1016/j.jad.2011.03.017

6. Ng QX, Yong BZJ, Ho CYX, Lim DY, Yeo W-S. Early life sexual abuse is associated with increased suicide attempts: an update meta-analysis. J Psychiatr Res. 2018;99:129-141. doi:10.1016/j. jpsychires.2018.02.001

7. Chen X, Duan H, Xiao L, Gan J. Genetic and epigenetic alterations underlie oligodendroglia susceptibility and white matter etiology in psychiatric disorders. Front Genet. 2018;9:565. doi:10.3389/ fgene.2018.00565

8. LeWinn KZ, Connolly CG, Wu J, et al. White matter correlates of adolescent depression: structural evidence for frontolimbicdisconnectivity. $\mathrm{J} \mathrm{Am}$ Acad Child Adolesc Psychiatry. 2014;53(8):899-909, 909.e1-7. doi:10.1016/j.jaac.2014.04.021

9. van Velzen LS, Kelly S, Isaev D, et al. White matter disturbances in major depressive disorder: a coordinated analysis across 20 international cohorts in the ENIGMA MDD working group. Mol Psychiatry;2019:1-15. 
10. Coelho R, Viola TW, Walss-Bass C, Brietzke E, Grassi-Oliveira R. Childhood maltreatment and inflammatory markers: a systematic review. Acta Psychiatr Scand. 2014;129(3):180-192. doi:10.1111/ acps. 12217

11. Olson EA, Overbey TA, Ostrand CG, Pizzagalli DA, Rauch SL, Rosso IM. Childhood maltreatment experiences are associated with altered diffusion in occipito-temporal white matter pathways. Brain Behav. 2020;10(1):e01485. doi:10.1002/brb3.1485

12. Jensen SKG, Pangelinan M, Björnholm L, et al. Associations between prenatal, childhood, and adolescent stress and variations in white-matter properties in young men. Neuroimage. 2018;182:389-397. doi:10.1016/j.neuroimage.2017.10.033

13. Meinert S, Repple J, Nenadic I, et al. Reduced fractional anisotropy in depressed patients due to childhood maltreatment rather than diagnosis. Neuropsychopharmacology. 2019;44(12):2065-2072. doi:10.1038/s41386-019-0472-y

14. Huang GB, Zhao T, Muna SS, et al. Effects of chronic social defeat stress on behaviour, endoplasmic reticulum proteins and choline acetyltransferase in adolescent mice. Int $J$ Neuropsychopharmacol. 2013;16(7):1635-1647. doi:10.1017/S1461145713000060

15. Zhao T, Huang GB, Muna SS, et al. Effects of chronic social defeat stress on behavior and choline acetyltransferase, $78-\mathrm{kDa}$ glucose-regulated protein, and CCAAT/enhancer-binding protein (C/ EBP) homologous protein in adult mice. Psychopharmacology (Berl). 2013;228(2):217-230. doi:10.1007/s00213-013-3028-6

16. Bagalkot TR, Jin HM, Prabhu VV, et al. Chronic social defeat stress increases dopamine D2 receptor dimerization in the prefrontal cortex of adult mice. Neuroscience. 2015;311:444-452. doi:10.1016/j. neuroscience.2015.10.024

17. Jin HM, Shrestha Muna S, Bagalkot TR, Cui Y, Yadav BK, Chung YC. The effects of social defeat on behavior and dopaminergic markers in mice. Neuroscience. 2015;288:167-177. doi:10.1016/j. neuroscience.2014.12.043

18. Watt MJ, Burke AR, Renner KJ, Forster GL. Adolescent male rats exposed to social defeat exhibit altered anxiety behavior and limbic monoamines as adults. Behav Neurosci. 2009;123(3):564-576.

19. Mouri A, Ukai M, Uchida M, et al. Juvenile social defeat stress exposure persistently impairs social behaviors and neurogenesis. Neuropharmacology. 2018;133:23-37. doi:10.1016/j.neuropharm. 2018.01.016

20. Ver Hoeve ES, Kelly G, Luz S, Ghanshani S, Bhatnagar S. Shortterm and long-term effects of repeated social defeat during adolescence or adulthood in female rats. Neuroscience. 2013;249:63-73. doi:10.1016/j.neuroscience.2013.01.073

21. Yang Y, Zhang Y, Luo F, Li B. Chronic stress regulates NG2(+) cell maturation and myelination in the prefrontal cortex through induction of death receptor 6. Exp Neurol. 2016;277:202-214. doi:10.1016/j. expneurol.2016.01.003

22. Birey F, Kloc M, Chavali M, et al. Genetic and stress-induced loss of NG2 glia triggers emergence of depressive-like behaviors through reduced secretion of FGF2. Neuron. 2015;88(5):941-956. doi:10.1016/j.neuron.2015.10.046

23. Cathomas F, Azzinnari D, Bergamini G, et al. Oligodendrocyte gene expression is reduced by and influences effects of chronic social stress in mice. Genes Brain Behav. 2019;18(1):e12475. doi:10.1111/ gbb. 12475

24. Bonnefil V, Dietz K, Amatruda M, et al. Region-specific myelin differences define behavioral consequences of chronic social defeat stress in mice. Elife. 2019;8. doi:10.7554/eLife.40855

25. Lehmann ML, Weigel TK, Elkahloun AG, Herkenham M. Chronic social defeat reduces myelination in the mouse medial prefrontal cortex. Sci Rep. 2017;7(1):46548. doi:10.1038/srep46548

26. Fekkes M, Pijpers FIM, Verloove-Vanhorick SP. Bullying: who does what, when and where? Involvement of children, teachers and parents in bullying behavior. Health Educ Res. 2004;20(1):81-91. doi:10.1093/her/cyg100
27. Zhang H, Yan G, Xu H, et al. The recovery trajectory of adolescent social defeat stress-induced behavioral, (1)H-MRS metabolites and myelin changes in Balb/c mice. Sci Rep. 2016;6(1):27906. doi: $10.1038 /$ srep27906

28. Hinton EA, Li DC, Allen AG, Gourley SL. Social isolation in adolescence disrupts cortical development and goal-dependent decision-making in adulthood, despite social reintegration. eNeuro. 2019;6(5):ENEURO.0318-19.2019. doi:10.1523/ENEURO.031819.2019

29. Makinodan M, Rosen KM, Ito S, Corfas G. A critical period for social experience-dependent oligodendrocyte maturation and myelination. Science. 2012;337(6100):1357-1360. doi:10.1126/ science. 1220845

30. Simon C, Gotz M, Dimou L. Progenitors in the adult cerebral cortex: cell cycle properties and regulation by physiological stimuli and injury. Glia. 2011;59(6):869-881. doi:10.1002/glia.21156

31. McKenzie IA, Ohayon D, Li H, et al. Motor skill learning requires active central myelination. Science. 2014;346(6207):318-322. doi:10.1126/science. 1254960

32. Chetty S, Friedman AR, Taravosh-Lahn K, et al. Stress and glucocorticoids promote oligodendrogenesis in the adult hippocampus. $\mathrm{Mol}$ Psychiatry. 2014;19(12):1275-1283. doi:10.1038/mp.2013.190

33. Saul ML, Helmreich DL, Rehman S, Fudge JL. Proliferating cells in the adolescent rat amygdala: characterization and response to stress. Neuroscience. 2015;311:105-117. doi:10.1016/j. neuroscience.2015.10.003

34. Lupien SJ, Juster R-P, Raymond C, Marin M-F. The effects of chronic stress on the human brain: from neurotoxicity, to vulnerability, to opportunity. FrontNeuroendocrinol. 2018;49:91-105.

35. Lloyd AF, Davies CL, Miron VE. Microglia: origins, homeostasis, and roles in myelin repair. CurrOpinNeurobiol. 2017;47:113-120.

36. Hagemeyer N, Hanft KM, Akriditou MA, et al. Microglia contribute to normal myelinogenesis and to oligodendrocyte progenitor maintenance during adulthood. Acta Neuropathol. 2017;134(3):441-458. doi:10.1007/s00401-017-1747-1

37. Miron VE. Microglia-driven regulation of oligodendrocyte lineage cells, myelination, and remyelination. J Leukoc Biol. 2017;101 (5):1103-1108. doi:10.1189/jlb.3RI1116-494R

38. Andersen SL, Teicher MH. Stress, sensitive periods and maturational events in adolescent depression. Trends Neurosci. 2008;31 (4):183-191. doi:10.1016/j.tins.2008.01.004

39. Meyer G, Ferres-Torres R, Mas M. The effects of puberty and castration on hippocampal dendritic spines of mice. A Golgi study. Brain Res. 1978;155(1):108-112. doi:10.1016/0006-8993(78)90309-8

40. He J, Crews FT. Neurogenesis decreases during brain maturation from adolescence to adulthood. PharmacolBiochemBehav. 2007;86 (2):327-333.

41. Ibi D, Takuma K, Koike H, et al. Social isolation rearing-induced impairment of the hippocampal neurogenesis is associated with deficits in spatial memory and emotion-related behaviors in juvenile mice. J Neurochem. 2008;105(3):921-932. doi:10.1111/j.14714159.2007.05207.x

42. Lee J, Hamanaka G, Lo EH, Arai K. Heterogeneity of microglia and their differential roles in white matter pathology. CNS Neurosci Ther. 2019;25(12):1290-1298. doi:10.1111/cns.13266

43. Mason JL, Suzuki K, Chaplin DD, Matsushima GK. Interleukin1beta promotes repair of the CNS. J Neurosci. 2001;21 (18):7046-7052. doi:10.1523/JNEUROSCI.21-18-07046.2001

44. Pascual M, Pla A, Minarro J, Guerri C. Neuroimmune activation and myelin changes in adolescent rats exposed to high-dose alcohol and associated cognitive dysfunction: a review with reference to human adolescent drinking. Alcohol Alcohol. 2014;49(2):187-192. doi:10.1093/alcalc/agt164

45. Merrill JE. Effects of interleukin-1 and tumor necrosis factor-alpha on astrocytes, microglia, oligodendrocytes, and glial precursors in vitro. Dev Neurosci. 1991;13(3):130-137. doi:10.1159/000112150 
46. Singh I, Pahan K, Khan M, Singh AK. Cytokine-mediated induction of ceramide production is redox-sensitive.implications to proinflammatory cytokine-mediated apoptosis in demyelinating diseases. J BiolChem. 1998;273(32):20354-20362.

47. Takahashi JL, Giuliani F, Power C, Imai Y, Yong VW. Interleukin-1 $\beta$ promotes oligodendrocyte death through glutamate excitotoxicity. Ann Neurol. 2003;53(5):588-595. doi:10.1002/ana.10519

48. Flygt J, Ruscher K, Norberg A, et al. Neutralization of interleukin-1beta following diffuse traumatic brain injury in the mouse attenuates the loss of mature oligodendrocytes. J Neurotrauma. 2018;35(23):2837-2849. doi:10.1089/neu.2018.5660

49. Vela JM, Molina-Holgado E, Arevalo-Martin A, Almazan G, Guaza C. Interleukin-1 regulates proliferation and differentiation of oligodendrocyte progenitor cells. Mol Cell Neurosci. 2002;20 (3):489-502. doi:10.1006/mcne.2002.1127

50. Stein DJ, Vasconcelos MF, Albrechet-Souza L, Cereser KMM, de Almeida RMM. Microglial over-activation by social defeat stress contributes to anxiety- and depressive-like behaviors. Front Behav Neurosci. 2017;11:207.

51. Rodriguez-Arias M, Montagud-Romero S, Guardia Carrion AM, et al. Social stress during adolescence activates long-term microglia inflammation insult in reward processing nuclei. PLoS One. 2018;13 (10):e0206421. doi:10.1371/journal.pone.0206421

52. Lehmann ML, Weigel TK, Cooper HA, Elkahloun AG, Kigar SL, Herkenham M. Decoding microglia responses to psychosocial stress reveals blood-brain barrier breakdown that may drive stress susceptibility. Sci Rep. 2018;8(1):11240. doi:10.1038/s41598-01828737-8

53. Kreisel T, Frank MG, Licht T, et al. Dynamic microglial alterations underlie stress-induced depressive-like behavior and suppressed neurogenesis. Mol Psychiatry. 2014;19(6):699-709. doi:10.1038/ mp.2013.155

54. Nie X, Kitaoka S, Tanaka K, et al. The innate immune receptors TLR2/4 mediate repeated social defeat stress-induced social avoidance through prefrontal microglial activation. Neuron. 2018;99 (3):464-479 e467. doi:10.1016/j.neuron.2018.06.035

55. Rothaug M, Becker-Pauly C, Rose-John S. The role of interleukin-6 signaling in nervous tissue. Biochim Biophys Acta. 2016;1863(6 Pt A):1218-1227.
56. Makinodan M, Ikawa D, Miyamoto Y, et al. Social isolation impairs remyelination in mice through modulation of IL-6. FASEB J. 2016;30 (12):4267-4274. doi:10.1096/fj.201600537R

57. Yu WC, Liu CY, Lai WS. Repeated, intermittent social defeat across the entire juvenile period resulted in behavioral, physiological, hormonal, immunological, and neurochemical alterations in young adult male golden hamsters. Front Behav Neurosci. 2016;10:110.

58. Roberts AG, Lopez-Duran NL. Developmental influences on stress response systems: implications for psychopathology vulnerability in adolescence. Compr Psychiatry. 2019;88:9-21. doi:10.1016/j. comppsych.2018.10.008

59. Burke AR, McCormick CM, Pellis SM, Lukkes JL. Impact of adolescent social experiences on behavior and neural circuits implicated in mental illnesses. Neurosci Biobehav Rev. 2017;76(Pt B):280-300.

60. McCrory E, De Brito SA, Viding E. The link between child abuse and psychopathology: a review of neurobiological and genetic research. $J$ Soc Med. 2012;105(4):151-156. doi:10.1258/ jrsm.2011.110222

61. Nemeroff CB. Paradise lost: the neurobiological and clinical consequences of child abuse and neglect. Neuron. 2016;89(5):892-909. doi:10.1016/j.neuron.2016.01.019

62. Kritas SK, Saggini A, Cerulli G, et al. Corticotropin-releasing hormone, microglia and mental disorders. Int $J$ Immunopathol Pharmacol. 2014;27(2):163-167. doi:10.1177/039463201402700203

63. Johnson JD, Barnard DF, Kulp AC, Mehta DM. Neuroendocrine regulation of brain cytokines after psychological stress. J Endocr Soc. 2019;3(7):1302-1320. doi:10.1210/js.2019-00053

64. Alonso G. Prolonged corticosterone treatment of adult rats inhibits the proliferation of oligodendrocyte progenitors present throughout white and gray matter regions of the brain. Glia. 2000;31 (3):219-231. doi:10.1002/1098-1136(200009)31:3<219::AIDGLIA30>3.0.CO;2-R

65. Liu Y, Ho RC, Mak A. Interleukin (IL)-6, tumour necrosis factor alpha (TNF-alpha) and soluble interleukin-2 receptors (sIL-2R) are elevated in patients with major depressive disorder: a meta-analysis and meta-regression. $J$ Affect Disord. 2012;139(3):230-239. doi:10.1016/j.jad.2011.08.003

66. Ng QX, Ramamoorthy K, Loke W, et al. Clinical role of aspirin in mood disorders: a systematic review. Brain Sci. 2019;9(11):296. doi:10.3390/brainsci9110296
Neuropsychiatric Disease and Treatment

\section{Publish your work in this journal}

Neuropsychiatric Disease and Treatment is an international, peerreviewed journal of clinical therapeutics and pharmacology focusing on concise rapid reporting of clinical or pre-clinical studies on a range of neuropsychiatric and neurological disorders. This journal is indexed on PubMed Central, the 'PsycINFO' database and CAS, and

\section{Dovepress}

is the official journal of The International Neuropsychiatric Association (INA). The manuscript management system is completely online and includes a very quick and fair peer-review system, which is all easy to use. Visit http://www.dovepress.com/testimonials.php to read real quotes from published authors. 